\title{
V \\ ENTRE O RIO E A FLORESTA: \\ O OLHAR DE DOIS CABLOCOS SOBRE A AMAZÔNIA BRASILEIRA*
}

\author{
Daniel Lima Fernandes ${ }^{1}$ \\ Raimundo Clecionaldo V asconcelos Neves ${ }^{2}$ \\ Anselmo Alencar Colares ${ }^{3}$
}

\section{Introdução}

O presente artigo tem por objetivo trazer para o debate teórico o olhar de dois caboclos amazônicos, sobre a região em vivem, não baseado somente na paisagem enquanto aparência, mais na busca da essência, dessa paisagem que revela o verdadeiro conhecimento.

O texto tem a pretensão de debater os caminhos e descaminhos da Amazônia relativos ao seu desenvolvimento regional, considerando que existem várias regionalizações desta região, tal debate terá como pano de fundo os conceitos de região, e desenvolvimento regional.

Quais os modelos de forma endógena ou exógena foram propostos como políticas de desenvolvimento para a Região Amazônica ao longo do processo histórico? Como esses modelos se refletem em uma cidade como Santarém na atualidade?

${ }^{*}$ DOI - 10.29388/978-65-86678-45-1-0-f.105-138

${ }^{1}$ Mestrando em Educação na Amazônia - Programa de Pós Graduação em Educação-PPGEUFOPA (2020).E-mail-daniel.fernandes@ifpa.edu.br

${ }^{2}$ Mestre em Teologia pela EST (2008). Mestrando em Educação pela UFOPA (2020). E-mail-cleo.neves@hotmail.com

${ }^{3}$ Doutor em Educação. Professor Titular da Universidade Federal do Oeste do Pará. Docente do Programa de Pós-graduação em Educação PPGE/UFOPA. Coordenador do Programa de Pósgraduação em Educação na Amazônia - Doutorado Acadêmico (Associação em Rede - Polo Santarém/UFOPA). Líder do Grupo de Estudos e Pesquisas "História, Sociedade e Educação no Brasil HISTEDBR/UFOPA". Presidente da Academia de Letras e Artes de Santarém (ALAS). Email: anselmo.colares@ufopa.edu.br. ORCID: http://orcid.org/0000-0002-1767-5640 


\section{$O$ conceito de região entre o singular e o universal}

Segundo Gomes, (1995, p.53) a palavra região deriva do latim regere (dirigir, comandar), regione na época do império romano eram áreas que possuíam uma administração local estavam subordinadas as magistraturas sediadas em Roma, tendo dessa forma a relação entre a centralização do poder em um local e a extensão dele sobre uma área de grande diversidade social, cultural e espacial.

A região está relacionada a três grandes domínios. O primeiro está relacionado a linguagem cotidiana e ao senso comum. O segundo domínio é o administrativo sendo a região vista como uma unidade administrativa. O terceiro é o das ciências de forma em geral onde o conceito de região está associado a ideia de localização de determinados fenômenos.

Por sua vez Haesbaert $(1999$, p.18) destaca as características do conceito de região na obra de três autores clássicos da Geografia, Vidal de La Blache, Carl Sauer e Richard Hartshorne que de forma diferenciada mais com pontos em comum dissertam sobre o conceito de região.

Um dos pontos em comum é a singularidade ou diferenciação espacial de uma determinada área, esta singularidade ocorre no plano teórico e se torna concreto pela ação particular dos movimentos sociais que reforçam suas identidades no espaço vivido. Um segundo ponto é a coesão ou coerência em suas múltiplas dimensões baseada em aspectos naturais e humanos. Um terceiro aspecto é a continuidade das regiões, não se trabalhando com regiões em áreas descontinuas ou fragmentadas e por fim o trabalho com uma meso-escala que estaria relacionada com um nível subnacional relacionada ao Estado-nação.

$\mathrm{Na}$ contemporaneidade região pode ser conceituada segundo Gomes (1995, p.63)

A região é um uma classe de área, fruto de uma classificação geral que divide o espaço segundo critérios ou variáveis arbitrários que possuem justificativa no julgamento de sua relevância para uma certa explicação, a região é um conceito que funda uma reflexão política de base territorial, se ela coloca em jogo comunidades de 
interesses identificadas a uma certa área e, finalmente, se ela é sempre uma discussão entre os limites da autonomia face a um poder central, parece que estes elementos devem fazer parte desta nova definição em lugar de assumirmos de imediato uma solidariedade total com o senso comum que, neste caso da região, pode obscurecer um dado essencial: o fundamento político, de controle e gestão de um território.

Com base neste conceito podemos classificar as regiões usando inúmeras dimensões, tais como a dimensão natural (bioma, clima, hidrografia) a dimensão urbano econômica, a dimensão política relacionados ao processo de regionalização tendo como pando de fundo o conceito de território, tais dimensões são utilizadas dependendo de qual é o objetivo do pesquisador. Uma das características principais do conceito está relacionado com a individualidade e as características específicas de um determinado recorte territorial.

Já segundo Haesbaert (1999, p. 29) região é

[...] um espaço não institucionalizado como Estado-nação de identidade ideológico-cultural e representatividade política, articulado em função de interesses específicos geralmente econômicos, por uma fração ou bloco regional de classe que nele reconhece sua base territorial de reprodução. Região é um conceito e regionalização é um método de análise, podendo qualquer espaço ser objeto de regionalização dependendo dos objetivos definidos pelo pesquisador.

Em seu conceito Haesbaert inclui as múltiplas dimensões de que uma região está revestida, as dimensões econômica, política, cultural, territorial tendo como agentes de sua criação tanto o Estado-Nação como grupos identitários, a região não é somente uma criação intelectual reforça o teórico mais se faz sentir no espaço vivido de grupos de representação, podendo influenciar tanto do ponto de vista do intelecto quanto do ponto de vista da ação no plano da realidade.

No trecho o autor enfatiza a diferença entre região e regionalização, destacando que qualquer área do espaço pode ser regionalizada, desde que possua as características de relacionadas ao conceito de região. 
Por sua vez Pedro Pinchas Geiger (1969) ${ }^{4}$ também destaca a relação entre região e regionalização "região, são porções diferenciadas da superfície terrestre e a regionalização é a forma atual de formação de regiões, no sentido estreito da palavra, como uma forma geográfica que surge apenas em determinada fase histórica de um território".

Em sua conceituação Pedro Geiger destaca a relação entre o conceito de região ao conceito de território, relação esta que perpassa pela criação do conceito de região enquanto teoria e a apropriação deste conceito enquanto espaço vivido.

\section{O processo de regionalização do Brasil}

Segundo dispõe Contel $^{5}$ (2019, p.4) antes da primeira divisão regional oficial criada pelo IBGE em 1942, algumas propostas tiveram significativa projeção nos meios intelectuais e mesmo em órgãos da administração pública, dentre as mais importantes divisões regionais do Brasil que fizeram parte dos debates que antecedem a divisão do IBGE, destacam-se as seguintes: a de André Rebouças (1889), dividindo o país em "10 áreas agrícolas", nesta proposta surge a regionalização da Amazônia onde consta três unidades federativas, Amazonas, Pará e Acre.

Por sua vez Elisée Reclus (1893), dividindo o país em 8 regiões, nesta proposta consta também três unidades federativas, o referido autor denomina como a primeira região de Amazônia e engloba o que hoje seria os estados do Amazonas, Pará e Acre.

Outra proposta foi de Said Ali (1905), propondo 5 regiões para o Brasil, Pierre Denis (1927), que dividiu o país em 6 regiões; e finalmente Betim Paes Leme (1937), com suas 7 regiões (tendo como principal critério a estrutura geológica do território, nesta proposta consta a chamada zona de sedimentação, que englobaria também três unidades federativas que hoje seriam Amazonas, Pará e Acre.

\footnotetext{
4 INSTITUTO BRASILEIRO DE GEOGRAFIA E ESTATISTICA- IBGE. Brasília-DF, Disponível em: https://biblioteca.ibge.gov.br/visualizacao/periodicos/115/rbg 1969 v31 n1.pdf. Acesso em 30 de julho de 2020.

${ }^{5}$ CONTEL, Fabio Betioli « As divisões regionais do IBGE no século XX (1942, 1970 e 1990) », Terra Brasilis (Nova Série) [Online], 3 | 2014, posto online no dia 26 agosto 2014, consultado o 23 abril 2019. URL http://journals.openedition.org/terrabrasilis/990 ; Acesso em: 30 jul. 2020.
} 
Já Delgado de Carvalho (1913), propõe a divisão do Brasil em 5 regiões: Brasil Setentrional ou Amazônia, Brasil Norte-Oriental, Brasil Oriental, Brasil Meridional e Brasil Central, sua obra Metodologia do Ensino da Geográfico (1925), destinada a professores, é apontada como a mais importante contribuição para o ensino da Geografia na primeira metade do século XX.

Em sua obra Geografia do Brasil, no Tomo I, definiu a regionalização que seria adotada oficialmente pelo IBGE em 1942, base da classificação vigente até os dias atuais, ocasião em que propõe o conceito de região natural como sendo a referência para o processo de regionalização do Brasil, que pode assim ser entendida nas palavras de Carvalho.

[...] a região natural é uma área geográfica, mais ou menos precisa, que a observação permite criar com a superposição de mapas figurando influências fisiográficas diferentes: relevo, hidrografia, clima, vegetação; forma-se, assim, uma imagem composta, uma síntese esboçada que vai servir de cenário à ação do homem (Carvalho, 1944, p. 16).

Nos anos 30 Getúlio Vargas chega ao poder através de um golpe de Estado, considerando que no processo eleitoral em que disputou a presidência o vencedor foi Júlio Prestes, seu governo (1930-1934) chamado de Governo Provisório, se consolida e alguns teóricos chamam de Revolução de 1930, que se constituiu de um movimento armado, liderado por militares e políticos dos Estados de Minas Gerais, Paraíba e Rio Grande do Sul.

Neste processo Getúlio Vargas inicia um desmantelamento do estado oligárquico, iniciando um movimento de institucionalização do Estado, é neste cenário no ano de 1938 que é criado o IBGE (Instituto Brasileiro de Geografia e Estatística), através do Decreto no. 218 de 26.01.1938 que culmina na junção do Conselho Brasileiro de Geografia com o Instituto Nacional de Estatística daria nascimento ao Instituto Brasileiro de Geografia e Estatística, o IBGE, neste momento as políticas territoriais passam a ser tratadas como prioridade de Estado, conside- 
rando o interesse em que o novo governo tem de centralizar o poder e diminuir o poder das oligarquias regionais.

No século XX, foram elaboradas pelo IBGE diversas divisões regionais contemplando os conceitos de Zonas Fisiográficas (década de 1940 e 1960), Microrregiões e Mesorregiões Homogêneas (1968 e 1976, respectivamente) e Mesorregiões e Microrregiões Geográficas (1990).

O $\mathrm{IBGE}^{6}$ utiliza critérios diferenciados em suas regionalizações e também modifica a alocação dos Estados federados nas grandes regiões, em 1942, é proposto pela primeira vez à agregação de Unidades da Federação em Grandes Regiões definidas pelas características físicas do território brasileiro e institucionalizadas com as denominações de: Região Norte, Região Meio- Norte, Região Nordeste Ocidental, Região Nordeste Oriental, Região Leste Setentrional, Região Leste Meridional, Região Sul e Região Centro-Oeste.

Em consequência das transformações ocorridas no espaço geográfico brasileiro, nas décadas de 1950 e 1960, uma nova divisão em Macrorregiões foi elaborada, em 1970, introduzindo conceitos e métodos reveladores da importância crescente da articulação econômica e da estrutura urbana na compreensão do processo de organização do espaço brasileiro, que resultaram nas seguintes denominações: Região Norte, Região Nordeste, Região Sudeste, Região Sul e Região Centro-Oeste, que permanecem em vigor até o momento atual.

\section{A Amazônia enquanto região geoeconômica}

Os geógrafos Pedro Pinchas Geiger e Roberto Lobato Corrêa propõe uma nova forma de regionalização para o Brasil, que divide o país em complexos regionais, que seriam: Amazônia, Nordeste e CentroSul. Uma das características da proposta de Pedro Geiger é de que ao contrário das propostas oficiais do IBGE, ele não considera os limites políticos administrativos dos Estados federados, a lógica que prevalece são as relações inter-regionais e o papel que cada região exerce na dinâ-

\footnotetext{
${ }^{6}$ INSTITUTO BRASILEIRO DE GEOGRAFIA E ESTATISTICA- IBGE. Brasília-DF, Disponível em: https://www.ibge.gov.br/geociencias/organizacao-do-territorio/divisao-regional/ 15778-divisoes-regionais-do-brasil.html. Acesso em 30 de julho de 2020.
} 
mica econômica regional. Por sua vez Roberto Lobato Corrêa em sua proposta de regionalização considera os limites dos Estados federados.

Segundo afirma (CORREA ${ }^{7}, 1989$, p.4), para que se possa construir uma regionalização geoeconômica algumas característica devem existir para que se possa fazer a diferenciação entre as regiões geoeconômicas, tais como, distintas especializações produtivas e de modos de como essa produção se realiza envolvendo os meios de produção e as relações sociais de produção, diferentes formas materiais criadas pelo trabalho social em seu arranjo espacial e diferentes níveis de articulação inter-regional e internacional. Em sua proposta de regionalização geoeconômica para a Amazônia, a proposta do referido autor está assim explicitada.

Os processos sociais e econômicos que a partir da década de 1950 passaram a atuar sobre a organização espacial brasileira geraram, entre outras consequências, uma nova regionalização caracterizada por três grandes regiões, o Centro-Sul, o Nordeste e a Amazônia. A Amazônia, por sua vez, e definida pelas unidades da região Norte (Para, Amapá, Amazonas, Roraima, Acre e Rondônia) e mais os Estados de Mato Grosso, Tocantins e Maranhão. A Amazônia teve seu território ampliado, aproximando seus limites da denominada Amazônia Legal. (CORREA, 1989, p.1)

omo se observa na proposta de regionalização da Amazônia Roberto Corrêa inclui Estados do Centro-Oeste (Mato Grosso) e do Nordeste (Maranhão) em sua totalidade, diferentemente da regionalização proposta por Pedro Geiger. A proposta de se criar uma regionalização feita pelo IBGE ao longo do processo histórico é criticada pois desconsidera as dinâmicas inter-regionais se desloca da realidade e ignora a integração socioeconômica e histórico-geográfica dessas regiões. Segundo Albuquerque os complexos regionais brasileiros têm a seguinte delimitação:

\footnotetext{
${ }^{7}$ CORRÊA, Roberto Lobato. A organização regional do espaço brasileiro. In: Conferência na X Semana de Geografia do Departamento de Geociências da Universidade Federal de Santa Catarina, Florianópolis, maio de 1989.
} 
A Amazônia- Compreende toda a extensão da floresta Amazônica localizada em território brasileiro. Integrada por todos os estados da região Norte, além do Mato Grosso (exceto sua porção sul) e oeste do Maranhão. Centro-Sul- O complexo regional do Centro-Sul corresponde a quase um terço do território nacional, compreende aos estados das regiões Sul e Sudeste (exceto o extremo norte de Minas Gerais), ao estado de Goiás, Mato Grosso do Sul, extremo sul do Mato Grosso e extremo sul do Tocantins. Nordeste- O complexo regional do Nordeste vai desde a porção leste do Maranhão até o norte de Minas Gerais, incluindo todos os estados nordestinos. (ALBUQUERQUE, 2013, p.27)

Segundo afirma Pedro Geiger (GEIGER,1969, p.22) dentre os principais problemas do complexo geoeconômico da Amazônia está do construir pontos de apoio que sirvam de elo entre as redes de cidades desta região, enfatiza ainda que no processo de planejamento deve priorizar o uso sustentável dos recursos naturais. Neste sentido o complexo geoeconômico da Amazônia funcionaria como uma região funcional. ${ }^{8}$

Albuquerque ressalta que comparativamente em relação a área, a Região Norte (IBGE), tem uma área menor que a Amazônia geoeconômica, e a Amazônia Legal é maior em área do que a Amazônia geoeconômica.

Segundo afirma Pedro Geiger' (Geiger, 1969, p.6) a ciência negase a designar os domínios naturais como regiões e cuja a organização é uma forma de organização do espaço pelo homem, com base nesta consideração existem duas abordagens que se relaciona com a Amazônia na forma de domínios, uma proposta de domínio no interior do território brasileiro e outro que vai além do de nosso território.

\footnotetext{
8 A região funcional é aquela definida a partir de sua atividade econômica principal dentro de uma divisão territorial do trabalho. As regiões funcionais derivam da fragmentação do mundo resultante da divisão internacional do trabalho no interior do capitalismo mundial e se formam na esteira do processo de modernização seletiva dos territórios nacionais (Santos, 2003).

${ }^{9}$ GEIGER, PEDRO PINCHAS. Revista Brasileira de Geografia, Regionalização: Brasília-DF. https://biblioteca.ibge.gov.br/visualizacao/periodicos/115/rbg 1969 v31 n1.pdf. Acesso em 30 de julho de 2020 .
} 
Por sua vez Aziz Ab'Saber ${ }^{10}$ segundo Albuquerque (2013, p.91) possui uma proposta que divide o Brasil em domínios morfoclimáticos: Amazônico, Cerrado, Mares e Morro, Caatinga, Araucárias, Pradarias Zona Costeira e Faixas de Transição. O referido autor conceitua que o domínio morfoclimático consiste em um "conjunto espacial de certa ordem de grandeza territorial - centenas de milhares de quilômetros quadrados de área - onde haja um esquema coerente de feições de relevo, tipos de solo, formas de vegetação e condições climáticos-hidrológicas”. A wwf Brasil ${ }^{11}$ uma das maiores ONGs (Organizações Não Governamentais) que atua na Amazônia, descreve em poucas palavras a grandeza do Bioma Amazônia.

A Amazônia é uma floresta tropical úmida que se estende pela bacia hidrográfica do rio Amazonas, uma vasta área tropical natural, com área de aproximadamente 6,74 milhões $\mathrm{km} 2$, que se estende por oito países: Bolívia, Brasil, Colômbia, Equador, Guiana, Peru e Venezuela. O bioma Amazônia é quase do tamanho da bacia, com 6,7 milhões de $\mathrm{km}^{2}$. A maior parte desse bioma - 60,1\% - está em território brasileiro. Para se ter uma ideia de sua grandiosidade, se a Amazônia fosse um país, seria o sétimo maior do mundo. A Amazônia abriga um número enorme de plantas e animais existentes no planeta e a maior parte dessas espécies sequer foi estudada pelos cientistas. Até agora, já se tem a classificação científica de pelo menos 40 mil espécies vegetais, 427 mamíferos, 1.294 aves, 378 répteis, 427 anfíbios e cerca de 3 mil peixes da região. A vida silvestre da Amazônia compartilha o espaço com cerca de 30 milhões de pessoas. Nessa população, incluem-se mais de 220 grupos indígenas na Amazônia brasileira, além de comunidades tradicionais que dependem dos recursos naturais para sobreviver.

Em um pequeno trecho de texto, a Amazônia Transnacional baseado no Bioma Amazônia demonstra toda a sua grandeza, possuindo a

\footnotetext{
${ }^{10}$ ALBUQUERQUE, Maria Adailza Martins de Geografia sociedade e cotidiano: espaço brasileiro, volume 2/ Maria Adailza Martins de Albuquerque, José Francisco Bigotto, Márcio Vitiello. $3^{a}$ Ed. São Paulo: Escala Educacional, 2013.

11 WWF BRASIL. Biomas. Disponível em www.wwf.org.br/naturza brasileira/areas prioritárias/amazonia1/bioma amazonia/. Acesso em 30 de julho de 2020.
} 
maior bacia hidrográfica do mundo, maior rio do mundo, Rio Amazonas segundo o INPE, o maior aquífero do mundo Grande Amazônia, e uma mega biodiversidade e socio diversidade. Por sua vez Becker (BECKER, 2009, p.53) destaca a chamada Amazônia Transnacional abrangendo $1 / 20$ da superfície terrestre e a dois quintos da América do Sul, contendo um quinto da disponibilidade mundial da água doce (17\%) e um terço das florestas mundiais latifoliadas, a Amazônia pode ser considerada o coração ecológico do planeta.

\section{Os modelos de ocupação territorial e desenvolvimento regional}

Segundo Berta Becker ${ }^{12}(2009$, p.23) distingue-se três períodos históricos no processo de formação territorial da Amazônia:

Quadro 1: Períodos históricos na formação da região amazônica

\begin{tabular}{|c|c|c|}
\hline $\begin{array}{c}\text { Formação territorial } \\
(1616-1930)\end{array}$ & $\begin{array}{c}\text { Planejamento regional } \\
(1930-1985\end{array}$ & $\begin{array}{l}\text { A incógnita do } \\
\text { Heartland-1985... }\end{array}$ \\
\hline $\begin{array}{l}\text { *Apropriação do território } \\
\text { (1616-1777) } \\
\text { *Delineamento da } \\
\text { nia }(1850-1899) \\
\text { *Definição dos } \\
(1899-1930)\end{array}$ & $\begin{array}{l}\text { *Planejamento regional } \\
(1930-1985) \\
\text { *Início do planejamento } \\
(1930-1966) \\
\text { *A produção do espaço es- } \\
\text { tatal (1966-1985) }\end{array}$ & $\begin{array}{l}\text { *A fronteira socioam- } \\
\text { biental (1985-1996) } \\
\text { *Tendências atuais } \\
(1996-. . .)\end{array}$ \\
\hline
\end{tabular}

Fonte: Berta Becker/2009

Becker destaca ainda (2009) que no período de 1616 à 1850 ocorre o processo de apropriação do território pela coroa portuguesa para além do Tratado de Tordesilhas, sendo a base econômica de então a exportação das "drogas do sertão" (canela, cravo, anil, cacau, raízes aromáticas, sementes oleaginosas, madeiras, salsaparrilha etc.), que eram utilizadas na alimentação, construção naval, condimentação e farmacopeia europeia.

\footnotetext{
${ }^{12}$ BECKER, Berta K. Amazônia: geopolítica na virada do III milênio/ Bertha Becker- Rio de Janeiro: Garamond, 2009
} 
O delineamento da Amazônia ocorre quando aumenta a preocupação imperial com a internacionalização da navegação do Rio Amazonas a partir de 1850 se inicia o chamado "Ciclo da borracha". No período de 1899 a 1930 se define os limites da região através da diplomacia e do controle interno do território pelo exército brasileiro.

A autora destaca ainda a existência de três elementos que merecem destaque no período de formação da região: a) uma ocupação tardia dependente do mercado externo, b) A importância da geopolítica e c) A experiência e o confronto de modelos de ocupação territorial.

Ressalta a autora que inserção tardia da Amazônia, do Brasil e de toda a América Latina na chamada economia-mundo capitalista ocorre a partir do processo de expansão marítimo comercial de empresas europeias na chamada fase do capitalismo comercial, passando a ser o que a autora chama de "economia de fronteira" conceito este que ocupa lugar central em toda a pesquisa da mesma em relação a Amazônia, ressalta-se ainda que essa inserção na periferia da chamada economia-mundo ocorre através de momentos de valorização dos produtos amazônicos na economia internacional e momentos de estagnação.

Quanto a geopolítica, destaca que garantiu o controle do território pelos portugueses, os mesmos ao escolherem locais estratégicos para fixarem seus fortes que posteriormente se transformaram em povoados, vilas e cidades e a consolidação do princípio uti possidetis garantindo pelo Tratado de Madri foi uma primeira vitória na ocupação territorial, vitória esta que se manteve posteriormente com a autonomia do Brasil em relação à Portugal, tal fato é destacado por que sem um aumento populacional correspondente ao tamanho da área ou uma consolidação da economia foi mantida a soberania da região.

Por fim destaca Becker (2009) que se consolidou duas concepções distintas de ocupação territorial. Uma baseada numa visão externa ao território, que reafirma a soberania, no entanto privilegia a relação com a metrópole. Exemplos dessa concepção, são representados pela era do Marquês de Pombal durante o Brasil colônia no Império e no Ciclo da Borracha. A outra concep̧̧ão é baseada em uma visão interna do território, e está relacionado com os habitantes locais da Amazônia, representado pelas missões no período 
das "drogas do sertão" fato este contribui de forma inequívoca para a ocupação territorial da Amazônia.

\section{O planejamento regional e a criação da Amazônia legal}

A Amazônia pode ser definida de acordo com os limites biogeográficos (Bioma Amazônia), hidrográficos (Bacia Amazônica) e político (Amazônia Legal), no entanto, estes critérios podem se inter-relacionar por exemplo no próprio definição do que vem a ser a Amazônia Legal, que tem por base um critério político, no entanto, se vale dos limites propostos pelos limites biogeográficos da floresta no território brasileiro para nortear a área do que seria chamado de Amazônia Legal.

Segundo Ferreira (2006, p.2) no período de 1850 até 1950 a economia da Amazônia estava alicerçada na economia extrativa da borracha. No período de 1898 a 1919 ocorre o processo de superação da extração da borracha natural da Amazônia (extraída da floresta) pela borracha asiática produzida na forma de plantation. A crise da economia extrativa da borracha compreende o período de 1912-1942. No ano de 1910 a borracha asiática inicia a subida do processo de produção no mercado internacional, no ano de 1919 a Amazônia produz 50 mil toneladas de borracha e a Ásia produz 400 mil toneladas.

Com o advento da segunda guerra mundial (1939-1945) e a captura feita pelo Japão das áreas produtoras de borracha na Ásia, a borracha produzida na Amazônia passa a ter importância estratégica, para se contrapor ao Japão e garantir acesso a produção de borracha nos esforços da guerra os Estados Unidos assinam com o Brasil um acordo de cooperação econômica, o chamado Acordo de Washington, que prevê a exclusividade do fornecimento de borracha do Brasil para os EUA.

Este acordo termina no ano de 1947, e em 1946 se inicia no Brasil uma Assembleia Constituinte, considerando o processo de estagnação previsível para a Amazônia, as elites da região aproveitam a assembleia para propor a criação de uma política de desenvolvimento regional permanente para a Amazônia.

Quem assume o protagonismo desta ação é o Deputado Federal Leopoldo Peres do Estado do Amazonas. A inspiração para a criação 
desta política vem dos EUA através do Tenesse Valley Authority Act, de acordo com Segundo Ferreira (2006, p.6), esta política tem as seguintes características.

O modelo do Tenessee Valley Authority Act apresenta dois aspectos, um de caráter econômico, outro político, onde deveriam ter-se em consideração diversos fatores para alcançar melhores resultados na promoção do desenvolvimento regional, com base nas bacias hidrográficas. Entre os aspectos de caráter econômico, podemos mencionar que o investimento público deveria ser centrado na utilização dos recursos naturais existentes, como parte do esforço nacional de desenvolvimento. Para isto, os programas das bacias hidrográficas, se orientariam a proporcionar o capital social básico (rodovias, pontes, serviços em geral), desenvolver o potencial agrícola, principalmente mediante obras de irrigação e construção de hidroelétricas de uma região

Os esforços dos deputados constituintes da Amazônia resultam na aprovação do Art. 199 da Constituição de 1946 com o seguinte teor:

Art 199 - $\mathrm{Na}$ execução do plano de valorização econômica da Amazônia, a União aplicará, durante, pelo menos, vinte anos consecutivos, quantia não inferior a três por cento da sua renda tributária.

Parágrafo único - Os Estados e os Territórios daquela região, bem como os respectivos Municípios, reservarão para o mesmo fim, anualmente, três por cento das suas rendas tributárias. Os recursos de que trata este parágrafo serão aplicados por intermédio do Governo federal.

Ainda no Governo Getúlio Vargas foi aprovada a Lei a Lei 1.806/53 que tinha por objetivo regulamentar o Art. 199 da Constituição Federal do Brasil, e nesta lei que se cria a chamada Amazônia Legal, que fica limitada ao território brasileiro.

A primeira proposta de regionalização da Amazônia remonta a Lei 1.806/53, que dispõe sobre o Plano de Valorização Econômica da Amazônia (SPVEA), cria a superintendência da sua execução e dá outras 
providências, nesta lei está proposta a seguinte delimitação para a chamada Amazônia legal, que está circunscrita ao território brasileiro, em seu Art. $1^{\circ}$ destaca os objetivos do plano e no $2^{\circ}$ delimita a área da Amazônia.

Art. $1^{\circ}$ O Plano de Valorização Econômica da Amazônia, previsto no Art. 199 da Constituição, constitui um sistema de medidas, serviços, empreendimentos e obras, destinados a incrementar o desenvolvimento da produção extrativa e agrícola pecuária, mineral, industrial e o das relações de troca, no sentido de melhores padrões sociais de vida e bem-estar econômico das populações da região e da expansão da riqueza do País.

Em seu art. $2^{\circ}$ faz a delimitação do que a lei chama de Amazônia brasileira.

Art. $2^{\circ}$ A Amazônia brasileira, para efeito de planejamento econômico e execução do Plano definido nesta lei, abrange a região compreendida pelos Estados do Pará e do Amazonas, pelos territórios federais do Acre, Amapá, Guaporé e Rio Branco e ainda, a parte do Estado de Mato Grosso a norte do paralelo de $16^{\circ}$, a do Estado de Goiás a norte do paralelo de $13^{\circ}$ e a do Maranhão a oeste do meridiano de $44^{\circ}$.

Como se observa nessa proposta se fala ainda em territórios federais do Acre, Amapá, Guaporé e Rio de Branco. No Mato Grosso a área abrange os Vale dos rios Guaporé, Paraguai, Teles Pires, Juruena e Xingu, No Maranhão, abrange a vertente do Rio Tocantins. Ressalta-se que já no governo Juscelino Kubitschek (1956-1961) em seu Plano de Metas não consta uma proposta de projeto nacional para a Amazônia, o que possui é dentre as 30 metas propostas, a meta de $n^{\circ} 25$ propõe o estímulo a produção de borracha sintética, tecnologia esta ainda distante da realidade amazônica.

Essa proposta de delimitação vai se manter no tempo com pequenas modificações, decorrentes da criação da Sudam através da Lei 5.173/66- e da recriação da Sudam através da Lei 124/2007- no Gover- 
no Luiz Inácio Lula da Silva, após a sua extinção no ano de 2001 pelo Governo Fernando Henrique Cardoso, destaca-se ainda uma substantiva mudança na composição do conselho deliberativo da Sudam/Spvea entre as referidas leis.

Quadro 2: A delimitação da Amazônia Legal e a composição do conselho diretor da Sudam/Spvea

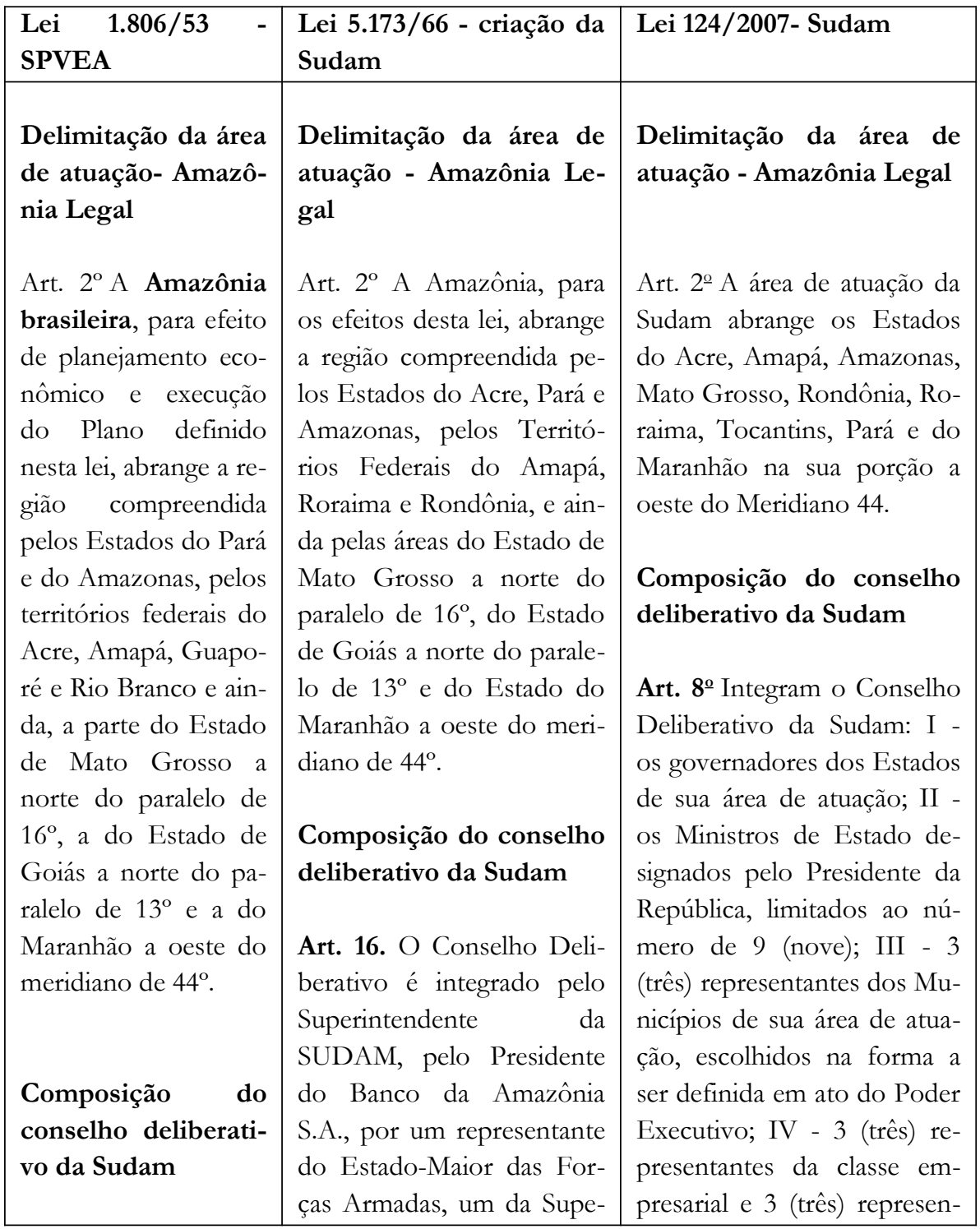




\begin{tabular}{|l|l|l|}
\hline Art. 24. O Superin- & rintendência da Zona Fran- & tantes da classe dos trabalha- \\
tendente presidirá a & ca de Manaus, um de cada & dores de sua área de atuação, \\
uma Comissão de de & Estado e Território inte- & indicados na forma a ser de- \\
Planejamento da Va- & grante da Amazônia, um do & finida em ato do Poder Exe- \\
lorização Econômica & Banco Nacional do Desen- & cutivo; V - o Superintenden- \\
da Amazônia, com- & volvimento Econômico, & te da Sudam; VI - O Presi- \\
posta de quinze mem- & um do Instituto Nacional & dente do Banco da Amazô- \\
bros sendo seis técni- & do Desenvolvimento Agrá- & nia S.A -BASA. \\
cos correspondentes & rio, um do Instituto Brasi- & \\
aos setores gerais de & leiro de Reforma Agrária, & \\
atividade que integra- & um da Fundação de Serviço & \\
rão o Plano, e nomea- & Especial de Saúde Pública, & \\
dos pelo Presidente & um do Conselho Nacional & \\
da República e nove & de Pesquisas e um de cada & \\
representantes dos & Ministério a seguir mencio- & \\
Estados e Território & nado; - Agricultura, Comu- & \\
Amazônicos um para & nicações, Educação e Cul- & \\
cada uma das entida- & tura, Fazenda, Minas e & \\
des administrativas & Energia, Planejamento, Re- & \\
interessadas, e desig- & lações Exteriores, Saúde, & \\
nados pelos respecti- & Indústria e Comércio, Tra- \\
vos governos. & balho e Previdência Social e & \\
Transportes. & \\
\hline
\end{tabular}

Fonte: Elaborado com base nas Leis Federais: 1.806/53 -SPVEA- 5.173/66criação da Sudam-124/2007- Nova Sudam

No tópico relativo a regionalização da Amazônia como se observa temos na Lei 5.173/66 o surgimento do Estado do Acre no lugar do território, por sua vez na Lei 114/2007 temos o desaparecimento de todos os territórios e em seu lugar surgem os Estados Federados, a permanência desse processo de regionalização denominado de Amazônia Legal com poucas alterações se deve ao fato de que a base dessa proposta é política e física considerando a área de abrangência do Bioma Amazônia no Brasil.

No entanto, no que concerne a composição do conselho deliberativo do órgão temos uma maior diferenciação. Na lei 1.803/53 temos somente a presença de técnicos, do superintendente e dos governadores. Já na lei surgem novos personagens: a Superintendência da Zona Franca de Manaus, do Banco de Desenvolvimento Econômico, do Incra, Fun- 
dação de Saúde Pública, Conselho Nacional de Pesquisa e a presença de 11 ministérios. Já em decorrência da Lei 124/2007, temos o surgimento entre os membros do conselho deliberativo a presença de representante dos municípios, a representação de 3 membros da classe empresarial e da classe trabalhadora, superintendente da própria Sudam e do Basa.

Um aspecto que deve ser observado nessa delimitação é que a influência do projeto do Tenesse Valley Authority Act (EUA) como referência de projeto de desenvolvimento regional, se confirma pois o referido projeto está totalmente baseado nas bacias hidrográficas daquela região, bem como, seus planos de desenvolvimento estão baseados nos recursos naturais existentes na área, tal influência se faz sentir na delimitação da chamada Amazônia Legal.

\section{Por uma política de desenvolvimento regional a criação da Spvea/Sudam}

A proposta de criar uma política de desenvolvimento regional para a Amazônia, se inicia com Superintendência do Plano de Valorização Econômica da Amazônia (SPVEA) criada através da Lei 1.806/53, seus objetivos eram apresentados com a retórica nacional-desenvolvimentista típica do período ${ }^{13}$

Com objetivos de assegurar à ocupação da Amazônia um sentido brasileiro, construir na Amazônia uma sociedade economicamente estável e progressiva capaz de, com seus próprios recursos, prover a execução de suas tarefas sociais e desenvolver a Amazônia num sentido paralelo e completar ao da economia brasileira... (SPVEA,1954).

Nos anos 1960 o Governo Federal, como estratégia para diminuir as tensões no campo especificamente nas regiões nordeste e sul e objetivando iniciar uma frente de expansão populacional e estendendo a

\footnotetext{
${ }^{13}$ FERREIRA, Pulga Mário Silvio. As origens da política brasileira de desenvolvimento regional: O caso da superintendência de valorização econômica da Amazônia (SPVEA). Instituto de Economia Unicamp. 2016. Disponível em https://www.eco.unicamp.br/images/arquivos/artigos/ 3461/TD266.pdf. Acesso em 30 de julho de 2020.
} 
fronteira econômica, ampliar o mercado interno e integrar a Amazônia ao restante do país os militares estimulam a vinda de trabalhadores rurais e de empresas para se instalar na Amazônia.

No Quadro 3 temos uma sintetize das diversas formas de financiamento do Estado na Amazônia Legal, percebe-se uma evolução nos instrumentos financeiros, evoluímos de uma porcentagem do orçamento para a consolidação de investimentos através de fundos inseridos na Constituição do Brasil.

Quadro 3: Fontes de financiamento na Amazônia Legal Sudam/Spvea

\begin{tabular}{|c|c|c|}
\hline Lei 1.806/53-SPVEA & $\begin{array}{l}\text { Lei } 5.173 / 66-\text { criação da } \\
\text { Sudam }\end{array}$ & $\begin{array}{l}\text { Lei } 124 / 2007-\text { Recria- } \\
\text { ção Sudam }\end{array}$ \\
\hline $\begin{array}{l}\text { Instrumentos de investi- } \\
\text { mentos financeiros da } \\
\text { Sudam } \\
\text { Art. } 8^{\circ} \text { Para atender à exe- } \\
\text { cução do Plano de Valori- } \\
\text { zação Econômica da Ama- } \\
\text { zônia é criado o Fundo de } \\
\text { Valorização Econômica da } \\
\text { Amazônia. } \int 1^{\circ} \text { O Fundo } \\
\text { de Valorização Econômica } \\
\text { da Amazônia será consti- } \\
\text { tuído com: a) } 3 \% \text { da renda } \\
\text { tributária da União; b) 3\% } \\
\text { da renda tributária dos Es- } \\
\text { tados, Territórios e Muni- } \\
\text { cípios, total ou parcial- } \\
\text { mente compreendidos na } \\
\text { área da Amazônia Brasilei- } \\
\text { ra (Art. } 2^{\circ} \text { ): c) as rendas } \\
\text { oriundas dos serviços do } \\
\text { Plano de Valorização Eco- } \\
\text { nômica da Amazônia, ou } \\
\text { sua exploração dos atos ou } \\
\text { contratos jurídicos dela } \\
\text { decorrentes; d) o produto } \\
\text { de operações de crédito e } \\
\text { de dotações extraordiná- }\end{array}$ & $\begin{array}{l}\text { Instrumentos de investi- } \\
\text { mentos financeiros da } \\
\text { Sudam } \\
\text { Art. 20. Constituem recur- } \\
\text { sos da SUDAM: I - dota- } \\
\text { ções plurianuais, nunca in- } \\
\text { feriores ao montante de } \\
\text { sua participação, no Plano } \\
\text { de Valorização Econômica } \\
\text { da Amazônia, consignadas } \\
\text { no Orçamento da União; } \\
\text { II - as dotações orçamen- } \\
\text { tárias ou créditos adicio- } \\
\text { nais que lhe sejam atribuí- } \\
\text { dos; III - o produto de } \\
\text { operações de crédito; IV - } \\
\text { o produto de juros de de- } \\
\text { pósitos bancários, de mul- } \\
\text { tas e emolumentos devidos } \\
\text { à SUDAM; V - a parcela } \\
\text { que lhe couber, do resulta- } \\
\text { do líquido das empresas de } \\
\text { que participe; VI - auxí- } \\
\text { lios, subvenções, contri- } \\
\text { buições e doações de enti- } \\
\text { dades públicas ou privadas, } \\
\text { nacionais, internacionais e }\end{array}$ & $\begin{array}{l}\text { Instrumentos de inves- } \\
\text { timentos financeiros } \\
\text { da Sudam } \\
\text { Art. 5o São instrumentos } \\
\text { de ação da Sudam: I - } \\
\text { planos regionais de de- } \\
\text { senvolvimento plurianu- } \\
\text { ais e anuais, articulados } \\
\text { com os planos federais, } \\
\text { estaduais e locais; II - o } \\
\text { Fundo Constitucional de } \\
\text { Financiamento do Norte } \\
\text { - FNO; III - o Fundo de } \\
\text { Desenvolvimento da } \\
\text { Amazônia - FDA; IV - } \\
\text { programas de incentivos } \\
\text { e benefícios fiscais e fi- } \\
\text { nanceiros, na forma da } \\
\text { lei e da Constituição Fe- } \\
\text { deral; V - outros instru- } \\
\text { mentos definidos em lei. }\end{array}$ \\
\hline
\end{tabular}




\begin{tabular}{|l|l|l|}
\hline rias da União, dos Estados & estrangeiras; VII - as ren- & \\
ou Municípios. $\int 2^{\circ}$ As & das provenientes de servi- & \\
rendas provenientes das & ços prestados; VIII - a sua & \\
percentagens mencionadas & renda patrimonial. Parág- & \\
nas alíneas a e b do parág- & rafo único. Os recursos & \\
rafo anterior serão recolhi- & não utilizados em um exer- & \\
das mensalmente às agên- & cício passarão aos exercí- & \\
cias do Banco do Brasil e & cios subsequentes. _Reda- & \\
creditadas ao Fundo de & ção dada pela Lei no 5.374, & \\
Valorização Econômica da & de 1967) & \\
Amazônia & & \\
\hline
\end{tabular}

Fonte: Elaborado com base nas Leis Federais: 1.806/53 -SPVEA5.173/66- criação da Sudam-124/2007- Nova Sudam

No quesito relativo aos instrumentos de execução financeira ou de planejamento, temos uma variação nas três leis, na Lei 1.803/53, existem a previsão do uso de 3\% da renda da União, Estados e Municípios, e está previsto a existência de um fundo de valorização da Amazônia, bem como, é condição básica a existência de planos de desenvolvimento para a aplicação desses recursos, no entanto, tais previsões não existem na Sudam relativo a Lei 5.173/66. A fonte de recursos previstos na Lei $124 / 2007$, são muito mais robustos, pois existe a previsão de diversos fundos de investimentos.

Os objetivos propostos no referido plano para a Amazônia são ambiciosos e não condizentes com a realidade do Brasil na década de 50, dentre os quais observamos, tais como, a defesa contra inundações periódicas, a promoção dos recursos minerais, empreendimentos que em muitos casos estão sendo desenvolvidos agora, o estímulo a industrialização das matérias primas da produção regional objetivando a venda para o mercado interno e externo, fato que infelizmente até os dias atuais não seja uma realidade na Amazônia, o estabelecimento uma política de energia para a região, política esta que somente nos dias atuais como a se tornar uma realidade.

Em seu artigo $24^{\circ}$ a lei prevê a participação dos representantes dos Estados em uma comissão responsável pela elaboração, execução e monitoramento do plano, mais não existe uma previsão de participação 
de representantes dos municípios e entidades da sociedade civil organizada.

Um outro destaque na referida lei é que os aspectos físicos da natureza relacionado ao Bioma Amazônia foi determinante na delimitação da região da Amazônia Legal, pois os limites da referida região seguem os limites deste bioma, tal fato fica evidente quando se inclui na referida região 24\% do território do Estado do Maranhão, ou seja o traçado da região segue os limites do Bioma e não dos Estados Federados, tais como, o próprio Estado do Maranhão.

\section{Entre o rio e a floresta da poesia a ciência}

Entre o rio e a floresta, o que poderia unir uma cientista a um poeta? João de Jesus de Paes Loureiro ${ }^{14}$ professor e poeta, responde, onde se localiza esse lugar mítico?

A margem do rio, entre o rio e a floresta, é o lugar privilegiado dos enigmas da Amazônia. Oferece interrogações sobe origens e destinos. É onde o rio desagua no imaginário. Quando se pode ler a multiplicidade dos ritmos da vida e do tempo, observar as indecisões entre da fronteira entre o real e a surrealidade.

Por sua vez a professora Berta Becker (2009), com outras palavras faz o mesmo questionamento, ao finalizar sua obra sobre os destinos da Amazônia, assim descreve sua última fase "A incógnita do Heartland (1985...)", traduzindo para o português, Heartland quer dizer "Aquilo que se desconhece e se deseja saber da terra do coração", podemos concluir que o enigma da margem do rio de João de Jesus de Paes Loureiro é o mesmo da terra do coração de Berta Becker, a ciência e a poesia unidas pelo coração. Além do coração a fala do poeta nos traz um conceito que é central de Berta Becker em sua pesquisa sobre a Amazônia, o conceito de Fronteira.

\footnotetext{
${ }^{14}$ LOUREIRO, João de Jesus de Paes. Meditação devaneante entre o rio e a floresta. Revistado Ppgartes. UFPA, 2016.
} 
Segundo Berta Becker (2009) o ano de 1985 nos traz dois processos opostos, de um lado o esgotamento do nacional desenvolvimentismo inaugurado na era Vargas com a intervenção do Estado na economia e no território, cujo último grande projeto foi o Projeto Calha Norte, no outro lado tem início a criação do Conselho Nacional dos Seringueiros (CNS), que é um símbolo da resistência das populações locais - autóctones e migrantes- à expropriação da terra.

No período de 1985 a 1996 soma-se a pressão ambientalista internacional e nacional um vetor tecno-ecológico (VTE), criando na Amazônia uma fronteira socioambiental através da execução de múltiplos projetos. ONGs, organizações religiosas, agências de desenvolvimento, partidos políticos, governos constroem novas territorialidades, tendo como estratégia básica a utilização das redes de comunicação que lhes permitem se articular com atores em várias escalas geográficas. Dentre esses atores internacionais destacam-se o G7 (Grupos das 7 economias mais ricas do mundo), que atua na Amazônia com o PP-G7- Programa Piloto para a Proteção das Florestas Tropicais Brasileiras, o Banco Mundial, se cria nesse período o Ministério do Meio Ambiente, dos Recursos Hídricos e da Amazônia Legal.

Esta fronteira socioambiental, cria um modelo de desenvolvimento endógeno, voltado para uma visão interna da região e para os habitantes locais, tendo dentre outros objetivos a defesa de um modelo de desenvolvimento que a partir de soluções locais busca solucionar problemas globais relativo ao Bioma Amazônia a partir da proteção da biodiversidade e da socio diversidade da Amazônia.

Em 1996, segundo Becker (1999), já no Governo Fernando Henrique Cardoso tem início uma nova fase no processo de ocupação regional, uma série de políticas paralelas e conflitantes, por isso explica a autora "a incógnita de heartland". Neste ano é retomado o Planejamento Territorial da União, fortalecendo um outro vetor de desenvolvimento denominado pela autora de termoindustrial (VTI), esse vetor reúne projeto de atores como empresários, bancos, segmentos de governos estaduais e federal e Forças Armadas, tal vetor se materializa pelos Programa Brasil em Ação (1996) e Avança Brasil (1999), pautados nos eixos nacionais de integração, estes programas favorecem a retomada de um modelo de for- 
ças exógenas que tem por meta a exploração de recursos para exportação, por esse motivo acaba conflitando com fronteira socioambiental.

Eis segundo Fernando Henrique Cardoso ${ }^{15}$ trecho do o programa Brasil em Ação que versa sobre a integração nacional:

\begin{abstract}
Programa Brasil em Ação (1996-1999) Integração NacionalEnfrentar os problemas estruturais e sociais do País com ações gerenciadas, em parceria com a iniciativa privada e com garantia efetiva de investimento. Esse é o princípio básico do Programa Brasil em Ação. A escolha dos projetos também atendeu à lógica dos Eixos Nacionais de Integração e Desenvolvimento, delineada no Plano Plurianual 1996-1999. Buscou-se um conjunto de empreendimentos estratégicos para promover a integração e o desenvolvimento do País como um todo, sem privilegiar uma ou outra região específica. Em decorrência dessa visão nacional, foram geradas oportunidades em todas as regiões, o que contribui para desconcentrar o desenvolvimento.
\end{abstract}

Em seu segundo mandato Fernando Henrique Cardoso propôs um novo programa o Programa Avança Brasil, os impactos previstos são extremamente danosos para a sustentabilidade da Floresta.

Destaca Berta Becker (1999) as forças da globalização entram em contradição ao mesmo tempo que pressionam e apoiam através de financiamento de projetos, e de redes globais de conectividade, visando a proteção e o uso sustentável da natureza, por outro lado estimula a derrubada da floresta, em decorrência da valorização da soja no mercado internacional. Hoje a Amazônia do ponto de visto geopolítico se constitui em uma fronteira do capital natural em nível global e como estratégia o olhar sobre a Amazônia deve ser a partir de sua transnacionalidade.

Uma dúvida surge é quanto ao esgotamento da região como fronteira de expansão demográfica e econômica nacional em direção ao sul do Estado do Amazonas, ao longo da Rodovia Santarém-Cuiabá e no centro leste do Pará, no entanto, esse movimento migratório é intrarregi-

\footnotetext{
${ }^{15}$ CARDOSO, Fernando Henrique. Programa Brasil em Ação. Brasília-DF, 1998. Disponível em https://web.archive.org/web/20110404114243/http://www.abrasil.gov.br/anexos/anexos2/ bact.htm. Acesso em 30 de julho de 2020.
} 
onal e não inter-regional. A valorização da soja, o lucro das madeireiras e da pecuária tem estimulado a retomada da fronteira.

A resistência e organização das populações tradicionais a expropriação de suas terras e identidades contam hoje com apoio de organizações religiosas, cientistas, nacionais e internacionais, e até de governos de países estrangeiros, mas esse sucesso político deve se transformar em sucesso econômico para as comunidades locais, que necessitam do apoio do Estado notadamente na infraestrutura.

\section{A cidade de Santarém como palco da relação entre forças endógenas e exógenas no desenvolvimento regional}

O Município de Santarém ${ }^{16}$ situa-se na parte centro-oeste do Estado do Pará, na mesorregião do Baixo Amazonas, microrregião de Santarém, é a sede da Região Metropolitana de Santarém, o segundo maior aglomerado urbano do Pará. Em uma localização privilegiada, está em torno de $800 \mathrm{~km}$ das maiores capitais da Amazônia: Belém e Manaus. E é cercada pelo Rio Tapajós, com vista para uma das mais belas paisagens da região amazônica: o encontro das águas límpidas do Tapajós com as águas turvas do Rio Amazonas.

E seus números comprovam essa grandeza ocupando uma área de $17.898 \mathrm{Km}^{2}$, sendo o $60^{\circ}$ no Brasil em área, o $13^{\circ}$ no Estado do Pará e o $3^{\circ}$ em sua microrregião. É o $3^{\circ}$ município mais populoso do Pará, o $7^{\circ}$ de toda a região norte e o $83^{\circ}$ do Brasil, com uma população estimada de 304 mil habitantes, de acordo com estimativa do Instituto Brasileiro de Geografia e Estatística (IBGE) em 2019. Segundo dados de 2014, possui um Produto Interno Bruto (PIB) de $\mathrm{R} \$ 3,7$ bilhões, ligado principalmente ao setor de serviços e comércio, mas também ao extrativismo e à indústria. É o sétimo município com maior PIB do estado. Santarém cidade histórica assim como a Amazônia brasileira possui uma série de ciclos em sua economia ao longo dos séculos conforme tabela adaptada abaixo.

\footnotetext{
${ }^{16}$ INSTITUTO BRASILEIRO DE GEOGRAFIA E ESTATISTICA- IBGE. Brasília-DF, Disponível em: https://cidades.ibge.gov.br/brasil/pa/santarem/panorama. Acesso em 30 de julho de 2020 .
} 
Quadro 4: Atividades produtivas Santarém 1600 a 2020

\begin{tabular}{|l|l|l|}
\hline & Dominante & Secundária \\
\hline Cacau e drogas do sertão & 1600 a 1700 & 1970 a 1990 \\
\hline Garimpo de ouro & 1940 a 1980 & 1990 a 2000 \\
\hline Borracha & 1850 a 1910 & 1980 a 2000 \\
\hline Juta-Curauá & 1940 a 1980 & 1990 a 2000 \\
\hline Gado-alimento básico & 1970 a 2000 & \\
\hline Fruta regional & 1990 a 2000 & \\
\hline Grão mecanizado & 2000 a 2020 & \\
\hline
\end{tabular}

Fonte: Adaptada de Scott William

Segundo Scott William Hoefle ${ }^{17}$, pesquisador da Universidade Federal do Rio de Janeiro, as características desses ciclos ou surtos como ele denomina se desenvolveu da seguinte forma:

Em tempos históricos, começando com o extrativismo das drogas do sertão no século XVIII, seguiram-se vários surtos econômicos de produção com fins comerciais, seguidos por períodos de estagnação econômica, que levaram a maior parte da mão de obra outrora engajada na atividade a regredir para a subsistência agrícola, e outra parte dos trabalhadores a se deslocar para outras áreas da Amazônia na tentativa de continuar a atividade em questão ou buscar outra em ascensão. Dessa forma, o desenvolvimento de diferentes atividades comerciais no oeste do Pará ora atraía, ora expulsava população, mas ao longo prazo, numa trajetória ascendente de aumento demográfico. O declínio de uma atividade nem sempre levou à sua total extinção, a atividade continuando em pequena escala durante décadas ou mesmo séculos ao lado de outras, podendo posteriormente ser retomada em novo contexto econômico.

\footnotetext{
${ }^{17}$ HOEFLE, Scott William, Santarém, Cidade Portal de Fronteiras Históricas do Oeste do Pará, Universidade Federal do Rio de Janeiro. Disponível em https://revistas.ufrj.br/index.php/EspacoAberto/article/view/2100. Acesso em 30 de julho de 2020.
} 


\section{A atuação dos movimentos sociais liderados pela Igreja Católica em Santarém}

Para a elaboração da análise, tomamos como inspiração, a realidade regional e a ecologia integral proposta pelo Papa Francisco e o Sínodo da Amazônia (ver LS.49 e 137; S da Amazônia 65 e 66). Outra referência importante é a mensagem do Papa Francisco no domingo de Páscoa passado aos Movimentos populares.

Santarém e municípios vizinhos têm sido palco de uma disputa de território, entre os Movimentos sociais/populares e o sistema capitalista predador. Como tudo está interligado, essa disputa faz parte de um confronto maior na Amazônia, no país e no mundo. Tratamos aqui o território que inclui a terra, as águas, com todos os viventes que nelas habitam e os recursos que estão abaixo do solo, a cidade, o campo, os meios de comunicação. Tudo está em disputa. Do lado do lado dos dominantes e do modo de produção econômica a serviço do grande capital na região, incluímos aqui: os empresários do agronegócio, os madeireiros, empresários do comércio, as empresas de exportação, especialmente a CARGILL, Empresa Brasileira de Postos de Santarém (EMBRAPS), Garimpeiros, empresários de construção civil e os grupos da especulação imobiliária.

Do lado dos Movimentos sociais/populares estão presentes em luta: os Sindicatos de Trabalhadores e Trabalhadoras Rurais (STTRs) de Belterra, Mojuí e Santarém, as federações de associações de Bairros/Comunidades, (Famcos e Unecos), o Grupo de defesa da Amazônia (GDA), o Centro de apoio a projetos de ação comunitária (Ceapac); Movimento em defesa do Urumari, o Conselho Indigenista Tapajós/Arapiuns (CITA); o Movimento Tapajós Vivo (MTV); Conselho comunitário de Alter do Chão; Movimento de trabalhadores em luta por moradia (MTLM); a organização Tapajoara da Resex Tapajós/Arapiuns, as ONGs: Projeto Saúde e Alegria (PSA); Federação de Órgãos para Assistência Social e Educacional (FASE), Sapopema, Terra de Direitos; e Pastorais Sociais da Arquidiocese de Santarém, entre tantos outros movimentos sociais que dialogam com a realidade local e regional. 
Por outro lado, tem havido avanços nas lutas populares. Há 10 anos o CITA não era reconhecido. Hoje a organização popular conquistou alguns direitos, como acesso indígena à universidade, demarcação de terras, já enfrentou um Juiz federal que cinco anos atrás chegou a duvidar e negar a existência dos povos indígenas na região.

Também o Movimento dos quilombolas da região ressurgiu em sintonia com a luta dos quilombolas nacionais e tem conquistado direitos à terra; Os STTRs têm lutado contra o agronegócio/agrotóxicos, promovido a agroecologia, e a luta em defesa do território na gleba Lago Grande; O Movimento Tapajós Vivo, tem trabalhado a construção do Protocolo de Consulta e Comitês de Bacias Hidrográficas, na região do rio Tapajós, que são duas ferramentas importantes na luta em defesa do território ameaçado pelo poder econômico.

Além disso realiza um projeto de implantação de bombeamento de água por energia solar em comunidades tapajônicas, como forma de lutar contra as hidroelétricas destruidoras da região; Na Gleba Lago Grande os movimentos populares estão numa luta firme em defesa do território ambicionado pela multinacional ALCOA, sedenta de bauxita. Ali, graças à Federação das Associações da Gleba Lago Grande FEAGLE, com apoio direto da FASE e do STTR está se conseguindo frear as ambições da ALCOA.

Pela Pastoral Social há dois grupos bem ativos na defesa dos povos nativos, um a Comissão Pastoral da Terra, presente na Resex Renascer e que apoia os lutadores sociais em Almeirim no confronto com a Empresa Jari. E a Pastoral dos Pescadores, tem apoiado as lutas dos pescadores contra as geleiras e contra a EMBRAPS que insiste em construir o porto bem na "boca" do lago do Maicá.

Esses são os principais resultados dos Movimentos sociais/populares em defesa dos povos e seus territórios, ativos na região. Uns mais, outros menos, como hoje são a FAMCOS e UNECOS e o GDA. Mas estão vivos. Até hoje a luta tem sido muito desigual, tanto pelo poder econômico apoiado pelos governantes, como pela fragilidade dos Movimentos sociais/populares, com falta de uma unidade na luta. Diante dessa realidade de luta por justiça social, defesa do meio ambiente, ecologia integral, como agem as lideranças da Igreja? 
É necessário repensarmos, sob pena, de negarmos o apelo evangélico o papel da Igreja diante dessas questões. Faz-se necessário refletir e repensar a ação da Igreja, sob pena de negarmos seu apelo evangelizador e seu papel histórico como agente de educação, de evangelização social, comprometida com os mais fragilizados. De que Igreja e de que Amazônia estamos falando? Como ela está? Para onde vai? O encontro dos bispos realizado em 2013 em Manaus foi uma retomada dos encontros ocorridos em 1952, 1972 e em 2012.

À luz do Espírito Santo, o resultado desse encontro indicou caminhos, diretrizes e opções para que a Igreja regional pudesse organizar, iluminar a vida e a missão no chão amazônico. Também, para que ocorresse a encarnação na realidade e para que a evangelização fosse libertadora, foram as diretrizes fundantes de um novo rosto da Igreja que passou a assumir opções marcantes dentro de um contexto de exclusão e marginalização e de crescentes ameaças às poucas conquistas obtidas nas últimas décadas. (a negação dos direitos fundamentais).

Assim, para viver a missionariedade e o profetismo da Igreja, foram assumidos compromissos que devem nortear toda a ação da Igreja na Amazônia: ser uma Igreja junto aos pobres (não apenas visitante, mas sendo presença), solidária com os excluídos e abandonados, também em momentos de enfrentamentos; contribuir para a mudança de mentalidade que considera a Amazônia colônia ou periferia do Brasil; estar ainda mais atenta à realidade desafiadora dos centros urbanos e dos grandes projetos que avançam a qualquer custo, esmagando toda forma de vida que se mostra como empecilho ou resistência.

Faz-se necessário, na atual conjuntura, formar e dinamizar comunidades e lideranças missionárias numa pedagogia que considere a vida e a realidade das pessoas, dando-lhes atenção e acompanhamentos necessários, a fim de que, abracem com convicção o seguimento de Jesus, sendo protagonistas da missão; viver o caminho da escuta da voz de Deus na Palavra Sagrada Escrita e nos gritos do povo denunciando erros e injusticas, apontando luzes e esperanças e empenhar-se para que a Igreja tenha, cada vez mais, rostos e corações amazônicos, na certeza de que Cristo, o Missionário do Pai, arma sua tenda na Amazônia. 
A Amazônia de que falamos não é a Amazônia idealizada pelos dominadores (potencializada, sobretudo, pelos meios de comunicação de massa), dominadores, exploradores, destruidores e aniquiladores dos povos da floresta. É latente a implantação de um projeto de dominação neoliberal, apoiado pelo atual presidente do Brasil Jair Bolsonaro, com políticas de desmontes de direitos fundamentais e de instituições (como o IBAMA, tendo seus servidores constantemente ameaçados, quando do cumprimento de suas atividades de proteção na Amazônia). Nota-se que as ações do governo Bolsonaro está e amparado pelo capital estrangeiro, como: Banco Mundial e organizações não governamentais - World Conservation Union, a World Resources Institute e pelo grupo dos paises mais ricos do mundo.

A Amazônia de que falamos é a Amazônia constituída de índios, negros, pardos, caboclos e imigrantes que vivem na e da floresta. Que convivem com os diversos e na adversidade. Que sabem cuidar, zelar e que defendem com a própria vida seu território. Essa gente tem rosto, gosto, traço e laços que caracterizam e revelam sua grandeza. Esses povos são muitas vezes invisibilizados pela ausência de políticas públicas e nós não nos reconhecemos neles, embora vindos deles. Há uma Amazônia da mata e uma Amazônia desmatada, entre outras Amazônias de contrastes.

A Amazônia de que falamos está dessacralizada, pobre de espírito. A força do rio não está mais livre. Ele foi barrado. A energia foi capturada e destinada aos complexos minerometalúrgicos, com as linhas de transmissão atravessando regiões cujas casas se iluminam com lamparinas, lampiões e velas. A Amazônia de que falamos é tratada de maneira descontextualizada dos países dos quais ela é parte. Existe uma Amazônia que resiste, mas, existe uma Amazônia que reexiste. Por quê?

A Igreja local precisa e deve posicionar-se, diante, sobretudo, do apelo do povo que clama por justiça. Os movimentos e pastorais precisam repensar suas práticas evangelizadoras, pois elas devem estar em sintonia com as diretrizes propostas e sugeridas no encontro dos bispos em Manaus e nas exortações do Papa Franciso. Não podemos virar o rosto, como se nada pudéssemos fazer. Cada carisma deve ser entendido como um serviço. Cada um por si é a mentalidade do capitalismo. Lembremos 
disso. Os movimentos eclesiais precisam ser e estar efetivamente usando seu carisma, mas, mergulhado na realidade local. Pensemos nos excluídos.

As Comunidades Eclesiais de Base - CEBs - estão envelhecendo, morrendo e não serão revitalizadas, se continuar esse modelo em curso. Aliás, as CEBs, as Novenas, as adorações são e devem ser espaços de fortalecimento espiritual para a caminhada. Mas, sente-se que são mais centros terapêuticos do que formativos. As pessoas estão preocupadas com os seus problemas individuais, com respostas para seus dilemas muitos dos quais de natureza material, econômica, e quase nunca pensando no outro, no coletivo, e na natureza que foi muito bem lembrada na Campanha da Fraternidade como sendo a nossa casa. Aliás, faz bem perguntar: que resultados aquela mensagem deixou nas mentes e nos corações? Parece difícil, mas a verdade revelada nessas práticas está adormecendo a capacidade de reflexão do povo, alimentadas pelos nossos padres, lideranças e do povo de Deus.

Os movimentos sociais, comprometidos realmente, estão sozinhos, como uma voz no deserto. Será que os bispos reunidos em Manaus viram uma realidade e nós estamos vendo outra? A pandemia está revelando que a realidade que fora jogada para debaixo do tapete, veio à tona. As máscaras caíram. Os pobres estão como Lázaro esperando cair de nossas mesas as migalhas de comida.

Porém precisamos fortalecer os movimentos pela luta em favor da preservação do meio ambiente (instalação do porto da Embraps, dos tanques de combustíveis na região do bairro do Uruará, ponte de concreto na praia do Maracanã), da dignidade das pessoas (apoio a iniciativa de acolhida das pessoas que vivem em situação de rua na sede do São Raimundo), da luta pela moradia (ocupação do Juá, combate ao uso desordenado da ocupação urbana). Essa realidade gera tantos Lárazos que estão cada vez mais distantes até mesmo das migalhas que caem das mesas dos abastados, tamanha é a distância que os separa.

\section{Considerações finais}


O processo de planejamento visando a criação de políticas de desenvolvimento no território brasileiro tem forte movimentação nos anos 30 com a criação do IBGE, e toma forma com as primeiras divisões desse órgão no final dos anos 30 e durante a década de 40. Com a reforma a constituinte de 46 se dá um passo decisivo que vai levar a criação da primeira política de desenvolvimento regional que se consolida nos anos 50 com a criação da SPVEA.

A política de desenvolvimento regional proposta para a Amazônia é de forma exógena, ou seja, de fora para dentro, parte do governo central, para a recém criada Amazônia Legal, nos anos 60, com a criação da SUDAM, uma nova política de desenvolvimento regional é proposta, o modelo exógeno permanece, pois a construção da política se dá de forma centralizada, partindo do governo central para a região, no entanto, como explicado no texto, ocorre de forma integrada envolvendo vários órgãos do Estado através de um programa de integração nacional, Nos anos 70 ocorre um processo de retração do modelo nacional desenvolvimentista decorrente crise do petróleo e nos anos 90, ocorre um novo revés com a extinção da SUDAM e da SUDENE.

Em 2007, ocorre retomada com a criação de uma política de desenvolvimento regional institucionalizada no Governo Lula através do Decreto 6.047/2007 que institui a Política Nacional de Desenvolvimento Regional (PNDR), em um modelo totalmente novo, deixando de ser uma política regional de desenvolvimento e passando a ser uma política nacional de desenvolvimento regional.

Em seu Art. $1^{\circ}$ está expresso, esta é uma política nacional de desenvolvimento regional, em que se vai trabalhar em múltiplas escalas de região e tem como principal objetivo reduzir as desigualdades nacionais. Neste Art. $1^{\circ}$ e Parágrafo Único, a PNDR já mostra toda a diferença em relação as propostas de desenvolvimento regional dos anos 30 a 90, criando no Brasil pela primeira vez uma política de desenvolvimento regional nacional e não direcionada somente para uma mesorregião.

A PNDR é uma política de desenvolvimento regional que trabalha diversas escalas, tais como, podemos observar no Art. $3^{\circ}$ do referido 
decreto, em escala macrorregional, mesorregional, mesorregiões diferenciadas e regiões integradas de desenvolvimento (RIDES).

Como se observa a PNDR, trabalha no nível nacional e em diversas escalas, o avanço de políticas de caráter endógeno ocorre exatamente porque modelo da acumulação flexível denominada de Toyotismo, que se desenvolveu no Japão, que se tornou um modelo alternativo ao Fordismo (EUA), facilitou o surgimento do paradigma de desenvolvimento endógeno como ressalta Julio Cesar Bellingieri (2017, p.15)

Por isso, a partir da década de 1980, surgiu o paradigma do desenvolvimento endógeno, segundo o qual o desenvolvimento não seria determinado pelo funcionamento das livres forças do mercado ou pelas políticas de planejamento territorial oriundas do poder central, mas, sim, por aspectos intrínsecos ao local, ao território, e pela sua capacidade de usar suas potencialidades de forma a conectarse ao sistema econômico global. Este paradigma contrapõese ao modelo de desenvolvimento em estágios, de Rostow (1978), rejeitando a necessidade de uma imitação mecânica das sociedades industriais e valorizando as especificidades de cada território.

Enfatiza Bellingieri que de forma contrária as teorias do Desenvolvimento Regional exógenos (de cima para baixo), o desenvolvimento endógeno pressupõe que os territórios locais são estratégicos no processo desenvolvimento considerando ao aproveitamento de todos os recursos socioeconômicos local, poderiam funcionar como forma de atrativo de atividades dinâmicas para o local, potencializando um desenvolvimento regional endógeno.

Conforme afirma Adriana Melo Alves (2014, p.327) ocorreu uma mudança de paradigma pois deixou de trabalhar somente na escala macrorregional e passou a trabalhar os problemas regionais em múltiplas escalas geográficas, destacou ainda a superação da abordagem exógena:

Superou a abordagem exógena, do tipo top-down, caracterizada pelas ações de implantação de grandes investimentos e sem o devido controle social, e propôs a valorização do desenvolvimento endógeno, do tipo bottom-up, com empoderamento, participação e con- 
trole social; Avançou na apuração do olhar sobre as regiões, superando a equivocada associação de que o "moderno" estaria atrelado às regiões mais desenvolvidas e o "arcaico" às menos desenvolvidas. Nesse sentido, a diversidade regional devia ser apreendida como um ativo a ser bem explorado economicamente.

Posteriormente foi incorporado em uma PNDR II como sendo princípio da política, um desenvolvimento regional que considere a valorização da diversidade territorial, ambiental, social, cultural e econômica. Essa política, além de reconhecer devidamente o que sempre foi visto como parte de nossa complexidade, destaca um elemento favorável para que o país se torne atrativo e, por assim dizer, competitivo.

No Art. $8^{\circ}$ PNDR (6.047/2007) está previsto a participação dos ministérios, representantes dos Estados e da sociedade civil através de um sistema de monitoramento. No entanto, o Governo Jair Bolsonaro aprovou o Decreto $n^{\circ} 9.810$, de 30 de maio de 2019, revogando a PNDR do Governo Lula e excluiu a participação popular, hoje de acordo com o referido decreto está previsto a participação somente de órgãos do governo em seus artigos $8^{\circ}$ a $11^{\circ}$ está previsto a participação somente de órgãos do governo federal foram excluídos também representantes dos Estados e municípios. No art. $5^{\circ}$ do referido decreto também foi excluída no processo de planejamento as microrregiões do IBGE. No art.12 no entanto está previsto como instrumento de planejamento a elaboração dos planos de desenvolvimento da Amazônia, Nordeste e Centro-Oeste.

\section{Referências}

\section{ALBUQUERQUE, Maria Adailza Martins de Geografia sociedade e cotidia-} no: espaço brasileiro, volume 2/ Maria Adailza Martins de Albuquerque, José Francisco Bigotto, Márcio Vitiello.3 ${ }^{a}$ Ed. São Paulo: Escala Educacional, 2013. ARTIGO-199 da Constituição federal de 18 de setembro de 1946, 2020. Disponível em https://www.jusbrasil.com.br/. Acesso em 30 em Julho de 2020.

BECKER, Berta K. Amazônia: geopolítica na virada do III milênio/ Bertha Becker- Rio de Janeiro: Garamond, 2009 
CARDOSO, Fernando Henrique. Programa Brasil em Ação. Brasília-DF, 1998. Disponível em https://web.archive.org/web/20110404114243/http:// www.abrasil.gov.br/anexos/anexos2/bact.htm. Acesso em 30 de julho de 2020.

CARDOSO, FH., and MÜLLER, G. Amazônia: expansão do capitalismo [online]. Rio de Janeiro: Centro Edelstein de Pesquisas Sociais, 2008.168 p. ISBN: 978-85-99662-73-1. Available from SciELO Books<http://books.scielo.org>.

CONTEL, Fabio Betioli «As divisões regionais do IBGE no século XX (1942, 1970 e 1990) », Terra Brasilis (Nova Série) [Online], 3 | 2014, posto online no dia 26 agosto 2014, consultado o 23 abril 2019. URL http://journals.openedition.org/terrabrasilis/990; DOI: 10.4000/terrabrasilis.990. Acesso em 30 de julho de 2020.

CORRÊA, Roberto Lobato. A organização regional do espaço brasileiro. In: Conferência na X Semana de Geografia do Departamento de Geociências da Universidade Federal de Santa Catarina, Florianópolis, maio de 1989.

FERREIRA, Pulga Mário Silvio. As origens da política brasileira de desenvolvimento regional: $O$ caso da superintendência de valorização econômica da Amazônia (SPVEA). Instituto de Economia Unicamp. 2016. Disponível em https://www.eco.unicamp.br/images/arquivos/artigos/3461/ TD266.pdf. Acesso em 30 de julho de 2020.

GEIGER, PEDRO PINCHAS. Revista Brasileira de Geografia, Regionalização: Brasília-DF. https://biblioteca.ibge.gov.br/visualizacao/periodicos/115/ rbg_1969_v31_n1.pdf. Acesso em 30 de julho de 2020.

HAESBAERT, ROGÉRIO. O território em tempos de globalização. Revista Eletrônica de Ciências Sociais Aplicadas e outras coisas. Departamento de Geografia da UERJ.Disponível em https://www.unifal-mg.edu.br/geres/files/ territorio\%20globaliza\%C3\%A7ao.pdf. Acesso em 30 de julho de 2020.

Índice de Progresso Social na Amazônia brasileira: IPS Amazônia 2014 / Daniel Santos; Danielle Celentano; Jaime Garcia; Antonio Aranibar; Adalberto Veríssimo - Belém, PA: Imazon; Social Progress Imperative, 2014.

INSTITUTO BRASILEIRO DE GEOGRAFIA E ESTATISTICA- IBGE. Brasília-DF, Disponível em: https://biblioteca.ibge.gov.br/visualizacao/periodicos/115/rbg_1969_v31_n1.pdf. Acesso em 30 de julho de 2020. 
INSTITUTO BRASILEIRO DE GEOGRAFIA E ESTATISTICA- IBGE. Brasília-DF, Disponível em: https://www.ibge.gov.br/geociencias/organizacao-do-territorio/divisao-regional/15778-divisoes-regionais-do-brasil.html. Acesso em 30 de julho de 2020.

INSTITUTO BRASILEIRO DE GEOGRAFIA E ESTATISTICA- IBGE. Brasília-DF, Disponível em: https://cidades.ibge.gov.br/brasil/pa/santarem/ panorama. Acesso em 30 de julho de 2020.

LOUREIRO, João de Jesus de Paes. Meditação devaneante entre o rio e a floresta. Revistado Ppgartes. UFPA, 2016.

MONTEIRO, Alcidema. O espaço amazônico: sociedade e meio ambiente. Belém-UFPA/NPI, 1997. 130 p.

POLITIZER, Georges. Princípios Fundamentais da Filosofia. Editora Hemus. São Paulo, Brasil. SÃO PAULO, Folha. Disponível em https://www1.folha.uol.com.br/fsp/ciencia/fe1511200001.htm. Acesso em 30 de julho de 2020.

WWF BRASIL. Biomas. Disponível em www.wwf.org.br/naturza brasileira/ areas prioritárias/amazonia1/bioma amazonia/. Acesso em 30 de julho de 2020 